\title{
Biomedical Sciences
}

Citation: Suárez-Quevedo Y, BarbosaVinasco HJ, Gutiérrez-Garnizo SA, et al. Innate trypanolytic factors in triatomine hemolymph against Trypanosoma rangeli and T. cruzi: A comparative study in eight Chagas disease vectors. Rev. Acad. Colomb. Cienc. Ex. Fis. Nat. 44(170):88-104, enero-marzo de 2020. doi: http://dx.doi. org/10.18257/raccefyn. 1097

Editor: Luis Fernando García

*Corresponding autor: Gustavo Adolfo Vallejo; gvallejo@ut.edu.co

Received: November 22, 2019 Accepted: January 20, 2020 Published: March 31, 2020

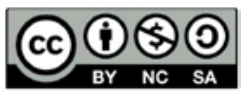

This is an open access article distributed under the terms of the Creative Commons Attribution License.
Original article

\section{Innate trypanolytic factors in triatomine hemolymph against Trypanosoma rangeli and T. cruzi: A comparative study in eight Chagas disease vectors}

\author{
Factores tripanolíticos innatos contra Trypanosoma rangeli \\ y T. cruzi en la hemolinfa de triatominos: un estudio \\ comparativo en ocho especies de vectores de la enfermedad \\ de Chagas
}

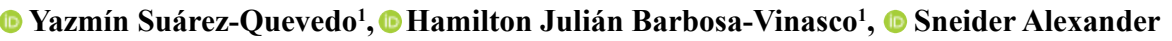

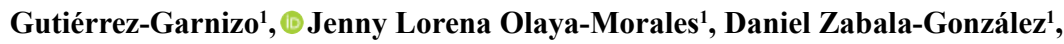

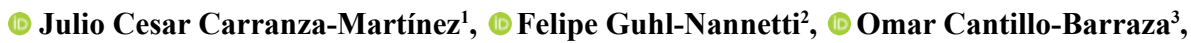 \\ (1) Gustavo Adolfo Vallejo ${ }^{1, *}$ \\ ${ }^{1}$ Laboratorio de Investigaciones en Parasitología Tropical (LIPT), Universidad del Tolima, Ibagué, Colombia \\ ${ }^{2}$ Centro de Investigaciones en Microbiología y Parasitología Tropical (CIMPAT), Universidad de Los Andes, \\ Bogotá, Colombia \\ ${ }^{3}$ Laboratorio de Referencia e Investigación en Enfermedades Tropicales, Dirección de Sanidad Ejército, \\ Ejército Nacional de Colombia, Bogotá, Colombia
}

\begin{abstract}
There is limited information about the innate immunity of triatomines against Trypanosoma rangeli, an infectious, non-pathogenic human parasite, and T. cruzi, the causative agent of Chagas' disease. This study aimed at addressing this gap by studying the in vitro trypanolytic hemolymph activity from insects not infected by $T$. rangeli or $T$. cruzi. Eight triatomine species were examined including Rhodnius prolixus, $R$. robustus, $R$. colombiensis, $R$. pallescens, $R$. pictipes, Triatoma dimidiata, $T$. maculata, and Panstrongylus geniculatus. The hemolymph of $R$. prolixus and $R$. robustus laboratory colonies demonstrated strong trypanolytic activity during the first 14 hours of parasite incubation with $81 \%$ lysis for the $T$. rangeli $\mathrm{C}$ genotype, $90 \%$ for the E genotype, $95 \%$ for $T$. cruzi discrete taxonomic unit (DTU) TcII, $94 \%$ for TcV, 96\% for TcVI, 94\% for Tcbat, and 90\% for Tcmarinkellei. No lysis activity was detected 14 or 24 hours after parasite incubation with the hemolymph of insects from $R$. pictipes R. pallescens, P. geniculatus, and T. maculata colonies. Identical results (absence of lysis) were observed using hemolymph from $R$. colombiensis and T. dimidiata laboratory colonies and specimens captured in sylvatic environments. The hemolymph lytic activity against recently obtained cultures (95\% decrease in live parasite count) and long-term $T$. cruzi TcII ones (96\% decrease) was similar. Lytic activity was similar in hemolymph from $R$. prolixus nymphs, males and females and insects fed on chicken or mouse blood. This is the first comparative study of the trypanolytic activity of hemolymph from different triatomine species against T. rangeli and $T$. cruzi genotypes. Although the chemical structures of such lysis factors and the mechanisms determining their expression have not been fully determined, their identification furthers our understanding of triatomines' innate immunity and their role in Trypanosoma transmission.
\end{abstract}

Keywords: Trypanosoma cruzi; Trypanosoma rangeli; Rhodnius prolixus; Rhodnius robustus; trypanolytic factors; vectorial ability; insect immunity

\section{Resumen}

Hay poca información sobre la inmunidad innata de los triatominos contra Trypanosoma rangeli, un parásito infeccioso para el humano, aunque no patógeno, y $T$. cruzi, el agente causal de la enfermedad de Chagas. En este trabajo se buscó llenar ese vacío mediante el estudio de la 
actividad tripanolítica in vitro de la hemolinfa de insectos no infectados con T. rangeli o T. cruzi. Se examinaron ocho especies de triatominos: Rhodnius prolixus, $R$. robustus, $R$. colombiensis, $R$. pallescens, $R$. pictipes, Triatoma dimidiata, T. maculata, y Panstrongylus geniculatus. La hemolinfa de las colonias de laboratorio de $R$. prolixus y $R$. robustus presentó una fuerte actividad tripanolítica durante las primeras 14 horas de incubación con los parásitos, evidenciando 81 y $90 \%$ de lisis para los genotipos $\mathrm{C}$ y E de T. rangeli y $95 \%$ para la unidad taxonómica discreta (DTU) de TcII, $94 \%$ para TcV, 96\% para TcVI, $94 \%$ para Tcbat y $90 \%$ para Tcmarinkellei. No se detectó lisis a las 14 ni a las 24 horas de incubación de los parásitos con las hemolinfas de colonias de laboratorio de $R$. pictipes, $R$. pallescens, $P$. geniculatus y $T$. maculata. Se registraron resultados idénticos (ausencia de lisis) con la hemolinfa de colonias de laboratorio de $R$. colombiensis y $T$. dimidiata y de especímenes capturados en ambientes selváticos. La actividad lítica de la hemolinfa fue similar en cultivos recientes de TcII ( $95 \%$ de lisis) y en aquellos mantenidos por periodos prolongados (96\% de lisis). La actividad lítica de la hemolinfa de $R$. prolixus fue similar en ninfas, machos y hembras y en insectos alimentados con sangre de gallina o sangre de ratón. Este es el primer estudio comparativo de la actividad tripanolítica en la hemolinfa de diferentes especies de triatominos contra genotipos de T. rangeli y $T$. cruzi. Aunque la estructura química de los factores líticos, así como los mecanismos que determinan su expresión, aún no se han establecido completamente, su identificación permitirá comprender mejor la inmunidad innata de los triatominos y su papel en la trasmisión de los tripanosomas.

Palabras clave: Trypanosoma cruzi; Trypanosoma rangeli; Rhodnius prolixus; Rhodnius robustus; factores tripanolíticos; Capacidad vectorial; Inmunidad en insectos.

\section{Introduction}

Trypanosoma rangeli, a non-pathogenic hemoflagellate capable of infecting a variety of mammalian species, including humans, is transmitted via triatomine insects belonging to the genus Rhodnius (Hoare, 1972; Guhl \& Vallejo, 2003). The interaction between the parasite and Rhodnius prolixus begins with the ingestion of blood containing trypomastigotes. Following ingestion, the parasites develop into epimastigotes in the intestine of the vector, where they come into contact with the products of blood digestion and other components of the midgut including the bacterial microbiota, hemolytic factors, lectins, the prophenoloxidase system, antimicrobial peptides, and reactive nitrogen and oxygen species (Vieira, et al., 2015). While these factors can act as biochemical barriers to T. rangeli infection, the parasite can still cause immunosuppression in $R$. prolixus by inhibiting processes such as phagocytosis, microaggregation of hemocytes, prophenoloxidase activation, and eicosanoid synthesis (Figueiredo, et al., 2008; García, et

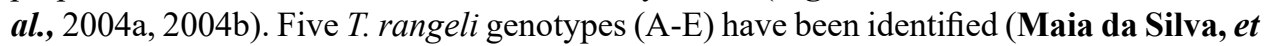
al., 2007; Vallejo, et al., 2015); however, we do not know whether all genotypes are capable of crossing the intestinal cell wall in $R$. prolixus, where they multiply in the hemocoel, migrate to the salivary glands, and produce infectious metacyclic trypomastigotes to complete their life cycle.

Trypanosoma cruzi, the etiologic agent of Chagas disease, is transmitted by more than 140 species of triatomines (Galvao \& Justi, 2015). Blood trypomastigotes are ingested by the vector in the intestine and then they progress to the amastigote, epimastigote, and spheromastigote developmental stages before they are finally eliminated in the feces as infectious metacyclic trypomastigotes (Vallejo, et al., 1988). All T. cruzi strains, which are classified into six discrete-typing units (DTU) (TcI-TcVI) (Zingales, et al., 2009, 2012), as well as the more recently identified Tcbat (Marcili, et al., 2009) and T. cruzi marinkellei strains (Barker, et al., 1978), remain exclusively within the intestine of the insect vector where they interact with the intestinal microbiota and counteract the effects of host defense factors such as defensins (López, et al., 2003; Vieira, et al., 2016), prolixicins (Ursic-Bedoya, et al., 2011), lysozymes (Buarque, et al., 2013; UrsicBedoya, et al., 2008), lectins (Pereira, et al., 1981; Mello, et al., 1996), components of the phenoloxidase cascade (Castro, et al., 2012; De Fuentes-Vicente, et al., 2016), and nitric oxide (Whitten, et al., 2007). 
In a previous study, Pulido, et al. identified differential lytic activity against $T$. rangeli strains in hemolymph from $R$. prolixus colonies fed on chicken blood and maintained for 10 years in the laboratory (Pulido, et al., 2008). Similarly, Mello, et al. showed differential trypanolytic activity against different $T$. cruzi strains in hemolymph from a 20 -year-old colony of $R$. prolixus fed on citrated rabbit blood (Mello, et al., 1996). These results indicate that $R$. prolixus can generate trypanolytic factors in hemolymph without prior exposure to $T$. rangeli or $T$. cruzi, which may have some effect on parasite development. While the factors responsible for this lytic activity have yet to be fully characterized, they are likely to be related to a systemic immune response of the vector to other microorganisms of the intestinal microbiota.

To understand the dynamics of parasite transmission, a tripartite approach focusing on triatomine-trypanosome-microbiome interactions has been proposed, which requires the integration of microbiological, genomic, ecological, bioinformatics, biochemical, and biological techniques to explain these interactions and how they may affect the transmission of trypanosomes (Salcedo-Porras \& Lowenberger, 2019). To achieve this, it is necessary to use both wild and established triatomine colonies with different microbiota from geographically distinct locations together with Trypanosoma strains with different genotypes and DTUs to study innate immunity and links with the biology of trypanosomes that could be exploited to reduce parasite transmission (Salcedo-Porras \& Lowenberger, 2019).

Our search of current literature revealed little information on the presence of innate trypanolytic factors in the hemolymph of triatomines other than $R$. prolixus. Therefore, we aimed to examine laboratory populations of five Rhodnius species, Triatoma dimidiata, T. maculata, and Panstrongylus geniculatus, as well as wild populations of $R$. pallescens and $T$. dimidiata, for the presence of innate trypanolytic factors against a range of $T$. rangeli and T. cruzi strains belonging to different genotypes and discrete taxonomic units (DTUs). Additionally, we studied whether the trypanolytic activity was related to the sex and stage of the insect, the time parasites are kept in culture and the time of the colonies in the laboratory. This is the first comparative study on the innate trypanolytic activity of hemolymph among different triatomine species. The results of this study provide a basis for further studies aimed at characterizing the intestinal microbiota of triatomines, which may impact the innate immunity of the vector species, and at identifying the factors responsible for the lytic activity of the hemolymph against $T$. rangeli and $T$. cruzi and their possible role in the transmission of parasites.

\section{Materials and methods}

\section{Trypanosoma rangeli and Trypanosoma cruzi strains}

Trypanosoma rangeli strains belonging to genotypes $\mathrm{B}, \mathrm{D}$, and $\mathrm{E}$ and $T$. cruzi strains belonging to reference DTUs TcII-TcVI were provided by Dr. Martha G. Teixeira from the Institute of Biomedical Sciences at the University of São Paulo. These strains were removed from liquid nitrogen storage and thawed. Once they arrived at the Tropical Parasitology Research Laboratory (LIPT) at the University of Tolima, they were refrozen in liquid nitrogen. Aliquots were thawed and cultured as needed. The T. rangeli genotype A strain (Choachí) was maintained by mouse-culture- $R$. prolixus cyclic passes every 3 months, while the genotype $\mathrm{C}$ strain (R. col 0226) was maintained by mouse-culture-Rhodnius colombiensis cyclic passes every 3 months (Vallejo, et al., 1986). Clones of both domestic and sylvatic TcI, as well as Tcbat and T. cruzi marinkellei strains isolated from bats in Colombia and maintained in liquid nitrogen, were also used in this study. Additionally, TcI (MHOM/CO/03/CG) and TcII (Y) strains were maintained in ICR mice. T. cruzi DTUs and T. rangeli genotypes were confirmed using previously described molecular markers (Souto \& Zingales, 1993; Souto, et al., 1996; Brisse, et al., 2001; Villa, et al., 2013; Vallejo, et al., 2002; Maia da Silva, 2007). For assays involving T. cruzi, we used 36 representative strains belonging to DTUs TcI-TcVI and Tcbat, one domestic T. cruzi TcI clone, and 
one sylvatic T. cruzi TcI clone. For the assays involving T. rangeli, we used 23 strains representing genotypes A-E along with one Trypanosoma leeuwenhoeki strain (Table 1). T. cruzi strains were cultured at $28^{\circ} \mathrm{C}$ in biphasic Novy-McNeal-Nicolle/liver infusion tryptose medium supplemented with $10 \%$ fetal bovine serum while $T$. rangeli strains were cultured in biphasic Bacto ${ }^{\mathrm{TM}}$ beef medium supplemented with $10 \%$ fetal bovine serum.

Table 1. Strains of $T$. rangeli genotypes and $T$. cruzi DTUs used in this study

\begin{tabular}{|c|c|c|c|c|}
\hline $\begin{array}{l}T \text {, rangeli genotype or } T \text {. } \\
\text { cruzi DTU }\end{array}$ & Strain & Host & Geographical origin & $\begin{array}{c}\text { Lysis caused by } \\
R \text {. prolixus hemolymph }\end{array}$ \\
\hline T. rangeli $\mathrm{A}$ & Duran & Homo sapiens & Cundinamarca (Colombia) & - \\
\hline T. rangeli $\mathrm{A}$ & Choachi & R. prolixus (domestic) & Cundinamarca (Colombia) & - \\
\hline T. rangeli $\mathrm{A}$ & TrD P19 & R. prolixus (domestic) & Norte Santander (Colombia) & - \\
\hline T. rangeli $\mathrm{A}$ & $\operatorname{TrP} 500$ & R. prolixus (sylvatic) & Casanare (Colombia) & - \\
\hline T. rangeli $\mathrm{B}$ & Saimiri & Saimiri sciureus & Manaus (Brazil) & - \\
\hline T. rangeli $\mathrm{C}^{*}$ & Ort Q 09-1 & Artibeus lituratus & Ortega (Colombia) & + \\
\hline T. rangeli $\mathrm{C}$ & Ort Q 09-2 & A. lituratus & Ortega (Colombia) & + \\
\hline T. rangeli $\mathrm{C}$ & R. col 089 & R. colombiensis & Coyaima (Colombia) & + \\
\hline T. rangeli $\mathrm{C}$ & R. col 0201 & R. colombiensis & Coyaima (Colombia) & + \\
\hline T. rangeli $\mathrm{D}$ & SC-58 & Echimys dasythrix & Santa Catarina (Brazil) & - \\
\hline T. rangeli $\mathrm{E}$ & 643 & Platyrrinus lineatus & Miranda (Brazil) & + \\
\hline T. leeuwenhoeki & Tas 250 & Bradypus variegatus & Pacific Region (Colombia) & + \\
\hline T. cruzi I ** & Ort $1-5$ & R. colombiensis & Ortega (Colombia) & - \\
\hline T. cruzi I & $\operatorname{Dm} 28$ & Didelphis marsupialis & Coyaima (Colombia) & - \\
\hline T. cruzi I & 833 & H. sapiens & Pará (Brazil) & - \\
\hline T. cruzi I & D1 & D. marsupialis & Coyaima (Colombia) & - \\
\hline T.cruzi I domestic clone & $\mathrm{MHOM} / \mathrm{CO} / 03 / \mathrm{CG}$ & H. sapiens & Caquetá (Colombia) & - \\
\hline T. cruzi Id sylvatic clone & Rcol/02 & R. colombiensis & Coyaima (Colombia) & - \\
\hline T. cruzi II & $\mathrm{Y}$ & H. sapiens & Sao Paulo (Brazil) & + \\
\hline T. cruzi II & 139 & D. aurita & Sao Paulo (Brazil) & + \\
\hline T. cruzi III & MT 3663 & P. geniculatus & Amazonas (Brazil) & - \\
\hline T. cruzi IV & José Julio & H. sapiens & Amazonas (Brazil) & - \\
\hline T. cruzi $\mathrm{V}$ & 967 & H. sapiens & Bolivia & + \\
\hline T. cruzi VI & CL Brener & T. infestans & Rio Grande do Sul (Brazil) & + \\
\hline T. cruzi bat & Ortq07-1 & Artibeus lituratus & Ortega (Colombia) & + \\
\hline T. cruzi bat & Ortq07-2 & A. lituratus & Ortega (Colombia) & + \\
\hline T. cruzi bat & Ortq07-3 & A. lituratus & Ortega (Colombia) & + \\
\hline T. cruzi bat & Ortq08-1 & Carollia perspicilata & Ortega (Colombia) & + \\
\hline T. cruzi bat & Cha Q 11-2 & A. lituratus & Chaparral (Colombia) & + \\
\hline T. cruzi bat & Cha Q 12-1 & C. perspicilata & Chaparral (Colombia) & + \\
\hline T. cruzi marinkellei & Cha Q 08-1 & Phyllostomus hastatus & Chaparral (Colombia) & + \\
\hline T. cruzi marinkellei & Cha Q 08-2 & P. hastatus & Chaparral (Colombia) & + \\
\hline
\end{tabular}

* In addition to the four strains of $T$. rangeli $\mathrm{C}$ described, 13 strains of the same genotype that presented lysis caused by the hemolymph of R. prolixus were also tested.

** In addition to the six strains of $T$. cruzi I described in the table, 14 strains of this DTU that also presented resistance to lysis caused by the hemolymph of $R$. prolixus were tested.

+ : Presence of lysis 


\section{Triatomines}

In this study, we used fifth-instar nymphs and adults belonging to Colombian triatomine species $R$. colombiensis, $R$. pallescens, $R$. pictipes, $R$. prolixus (domestic), $R$. prolixus (sylvatic), $R$. robustus, $T$. dimidiata, $T$. maculata, and $P$. geniculatus, which were maintained in an insectary. The insects were fed weekly on chickens and housed in incubators with a 12 -h light $/ 12$-h dark photoperiod at $28^{\circ} \mathrm{C}$ and $80 \%$ relative humidity. Fifth-instar nymphs and adults belonging to the species $R$. colombiensis and T. dimidiata were also collected from sylvatic environments and used to obtain hemolymph for the analysis of their trypanolytic activity.

\section{Detection of trypanolytic activity against T. rangeli and T. cruzi in the hemolymph of} triatomines

Insects were fed on chickens 8 days before the assays. Hemolymph was collected by making a cut in the femur of the third hind leg and applying very slight abdominal pressure. Hemolymph samples from 20 individuals of each species were pooled and then centrifuged at $14,000 \times g$ for $5 \mathrm{~min}$. The resulting cell-free supernatant was used in trypanolytic activity assays performed as described previously by Pulido, et al. (2008). Briefly, to prevent melanization, $2 \mu \mathrm{l}$ of $50 \mathrm{mM}$ of phenylthiourea were added to each $100-\mu 1$ volume of hemolymph. Cultures of $T$. cruzi or T. rangeli were washed three times with $0.9 \%(\mathrm{w} / \mathrm{v})$ saline solution, centrifuged at $7000 \times \mathrm{g}$ for $5 \mathrm{~min}$, and then resuspended in $10 \%(\mathrm{v} / \mathrm{v})$ liver infusion tryptose medium. Ten microliters of hemolymph were then added to $10-\mu 1$ aliquots of parasite suspension at a final concentration of $2.5 \times$ $10^{7}$ parasites $/ \mathrm{ml}$. To assess the lytic activity, live parasites were counted in a Neubauer chamber after 0 and $14 \mathrm{~h}$ of incubation. A negative control consisting of hemolymph inactivated with $10 \mu \mathrm{l}$ of pepsin solution $(15 \mathrm{mg} / \mathrm{ml}$ in $1 \mathrm{M} \mathrm{HCl})$ per $100 \mu \mathrm{l}$ of hemolymph and incubated at $37^{\circ} \mathrm{C}$ for $4 \mathrm{~h}$ was included in all experiments. T. rangeli genotype $\mathrm{C}$ (Rcol 0226) and T. cruzi TcII (Y) strains were used as positive controls with both strains always lysed when incubated with hemolymph from $R$. prolixus. T. rangeli genotype A (Choachí) and T. cruzi TcI (Dm28) strains were used as negative control strains, which were not lysed when incubated with hemolymph from $R$. prolixus. For both the negative and positive controls, the parasites were resuspended at a final concentration of $2.5 \times 10^{7}$ parasites $/ \mathrm{ml}$. All assays were carried out in triplicate.

An underlying question of this study was whether keeping the triatomine colonies in the laboratory could affect the innate lytic factors, whereby lytic activity could be lost after several generations. To address this question, we collected $R$. colombiensis and T. dimidiata specimens from the field and used pooled hemolymph from each species in trypanolytic activity assays with the T. cruzi TcII (Y) strain. All controls described above were included in these assays. The results were compared with those obtained using colonies of the same species that had been maintained in the laboratory for 5 and 20 years.

We also investigated whether the long-term maintenance of cultured epimastigotes could affect their resistance to lysis. In these assays, $R$. prolixus hemolymph was incubated with $T$. cruzi TcII strain Y obtained from recent hemoculture of mouse blood or with $T$. cruzi TcII strain Y that had been kept in culture with weekly subcultures for 4 years. We also compared the lytic activity of hemolymph from vectors fed with chicken blood or mouse blood, and from $R$. prolixus nymphs, males, and females.

\section{Ethical aspects}

The project was approved by the Central Research and Scientific Development Committee at the University of Tolima after verifying that the proposed protocols were in accordance with the ethical standards laid down in Resolution 8430 of 1993 by the Colombian Ministry of Health for the handling of laboratory animals. The technicians in care of the animals at the LIPT observed all aspects related to their maintenance following strict regulations for ensuring the animals' consistent care and handling. 


\section{Statistical analysis}

Parasite counts at 0 and $14 \mathrm{~h}$ of incubation are presented as means \pm standard deviation. For strains showing lysis at $14 \mathrm{~h}$, the percentage of lysed cells was calculated by comparing with the number of parasites at $0 \mathrm{~h}$. T. rangeli and $T$. cruzi strains that were not lysed at $14 \mathrm{~h}$ were observed for $10 \mathrm{~h}$ more ( $24 \mathrm{~h}$ of incubation). We conducted a one-way analysis of variance (ANOVA) with Tukey's post hoc analysis to identify significant differences among the strains. The differences between the treatments and the controls were considered statistically significant at $\mathrm{p}<0.05$. Graphs were generated using the GraphPad Prism 5.0 software (GraphPad Software Inc., San Diego, CA, USA).

\section{Results}

\section{Effects of $R$. prolixus hemolymph on T. rangeli strains belonging to different genotypes}

The effects of $R$. prolixus hemolymph on the survival of T. rangeli genotype A (Choachí) and genotype $\mathrm{C}$ (Rcol0226) strains are shown in figure 1 . The T. rangeli genotype $\mathrm{C}$ strain showed an $86 \%$ decrease in live parasite numbers at the 14-h time point compared to those at time point 0 in the presence of native hemolymph but was not affected by incubation with the inactivated hemolymph. Instead, no changes in the live parasite counts of the $T$. rangeli genotype A strain were observed following incubation with either the inactivated or native hemolymph suggesting that it was not susceptible to the lytic effects of the hemolymph. Therefore, these two strains were used as the positive (presence of lysis) and negative (absence of lysis) controls, respectively, for all subsequent analyses of genotype $\mathrm{B}, \mathrm{D}$, and $\mathrm{E}$ T. rangeli strains.

Representative strains belonging to each of the remaining T. rangeli genotypes (B, $\mathrm{D}$, and $\mathrm{E}$ ) were then assessed for their susceptibility to the lytic activity of the $R$. prolixus hemolymph (Figure 2). No significant changes in the live parasite counts of genotype $\mathrm{A}, \mathrm{B}$, and D strains were observed after $14 \mathrm{~h}$ of incubation with either the inactivated or native hemolymph while $81 \%$ and $90 \%$ decreases in live parasite counts were observed for genotype $\mathrm{C}$ and $\mathrm{E}$ strains, respectively, following incubation with native hemolymph. The genotype A, B, and D strains remained resistant to lysis after $24 \mathrm{~h}$ of incubation (Table 2).

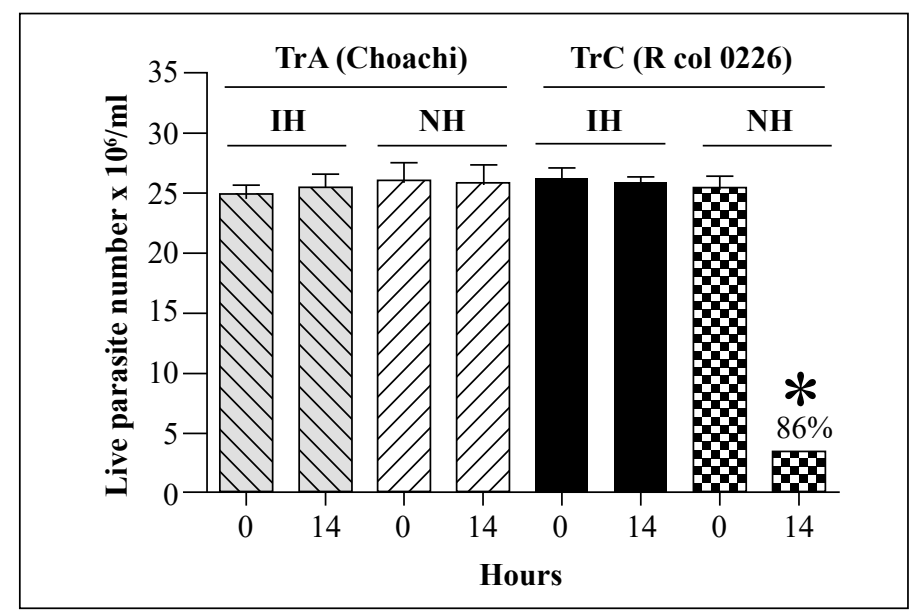

Figure 1. In vitro survival of T. rangeli genotype A (Choachí) and C (Rcol0226) strains following incubation with hemolymph from $R$. prolixus

Each bar represents the mean \pm SD of live parasite counts from three independent assays after 0 and $14 \mathrm{~h}$ of incubation. Each T. rangeli strain was incubated with inactivated hemolymph (IH) or native hemolymph $(\mathrm{NH})$.

*: $\mathrm{p}<0.05$ compared with the live parasite counts of genotypes A and $\mathrm{C}$ strains incubated with $\mathrm{NH}$ at the same time point. 


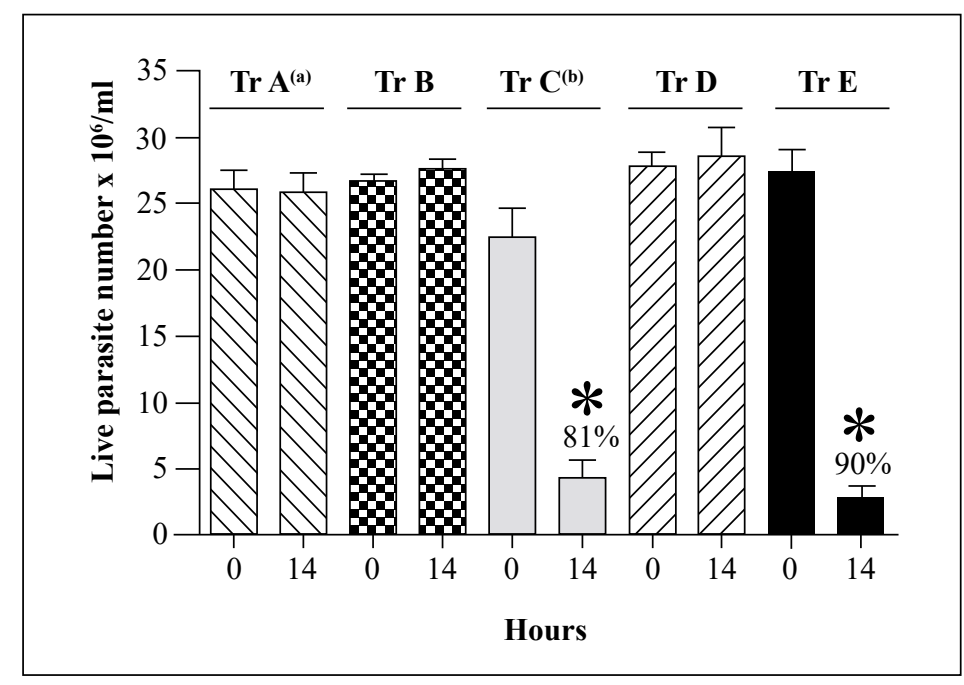

Figure 2. Summary of in vitro survival of genotypes A-E of T. rangeli strains following incubation with native hemolymph from $R$. prolixus

Each bar represents the mean $\pm \mathrm{SD}$ of live parasite counts from three independent assays after 0 and $14 \mathrm{~h}$ of incubation with native hemolymph. T. rangeli genotypes A (Choachí), B (Saimiri), C (Rcol0226), D (SC58), and E (643) strains were examined.

a: Lysis resistance was observed in four genotype A T. rangeli strains.

b: Lysis susceptibility was observed in 17 genotype $C$ T. rangeli strains. Only one strain was tested for each of B, D, and E genotypes (Table 1). The Rcol0226 and Choachí strains were used as the positive (presence of lysis) and negative (absence of lysis) controls, respectively, for analyses of genotypes $\mathrm{B}, \mathrm{D}$, and $\mathrm{E}$ strains.

$*: \mathrm{p}<0.05$ compared with the live parasite counts of the negative control with the native hemolymph $\mathrm{NH}$ at the same time point.

\section{Effects of R. prolixus hemolymph on T. cruzi strains belonging to different DTUs}

The effects of R. prolixus hemolymph on the survival of T. cruzi TcI (Dm28) and TcII (Y) strains were then examined (Figure 3). No significant changes in the live parasite counts of the T. cruzi TcI strain were observed following incubation with either the inactivated or native hemolymph. In contrast, there was a $95 \%$ decrease in live parasite numbers of the T. cruzi TcII strain (Y) after $14 \mathrm{~h}$ of incubation with the native hemolymph compared with the counts at time point 0 . As a result, T. cruzi TcI strain Dm28 and TcII strain Y were used as negative and positive controls, respectively, for all further assays.

We examined then the susceptibility of the remaining T. cruzi strains ( $\mathrm{TcIII}, \mathrm{TcV}$, TcVI, Tcbat, and Tcmarinkellei) to lysis by the hemolymph (Figure 4). Analysis of 20 TcI strains showed complete resistance to lysis in all cases. The TcIII strain showed only partial susceptibility to lysis with a $13 \%$ decrease in live parasite counts observed after 14 $\mathrm{h}$ of incubation with the native hemolymph compared with parasite counts at time point 0 . In contrast, decreases in live parasite counts of $95 \%, 94 \%, 96 \%, 94 \%$, and $90 \%$ were observed for the TcII, TcV, TcVI, Tcbat, and T. cruzi marinkellei strains, respectively, after $14 \mathrm{~h}$ of incubation with the native hemolymph. Interestingly, analysis of a TcIV strain (Jose Julio) revealed a high degree of agglutination but no evidence of lysis after $24 \mathrm{~h}$ of incubation with the native hemolymph (Table 2).

Table 2 summarises the results of the hemolymph lytic activity in eight triatomine species after 24 hours of incubation with representative strains from five $T$. rangeli genotypes, seven T. cruzi DTUs, and a T. cruzi subspecies. The T. rangeli $\mathrm{C}$ and $\mathrm{E}$ genotype strains and the DTU TcII, TcIII, TcV, TcVI, Tcbat, and the Tcmarinkellei strains were lysed by $R$. prolixus and $R$. robustus hemolymphs. T. rangeli genotype A and B strains and TcI strain were not lysed. The TcIV strain became agglutinated but not lysed. It is 
Table 2. Trypanolytic activity of hemolymph of eight triatomine species on epimastigotes of $T$. rangeli genotypes and $T$. cruzi DTUs at 24 hours of incubation

\begin{tabular}{|c|c|c|c|c|c|c|c|c|c|c|c|c|c|}
\hline $\begin{array}{l}\text { Vector } \\
\text { species }\end{array}$ & $\begin{array}{c}\text { T. rangeli } \\
\text { A } \\
\text { (Choachí) }\end{array}$ & $\begin{array}{c}\text { T. rangeli } \\
\text { B } \\
\text { (Saimiri) }\end{array}$ & $\begin{array}{c}\text { T. rangeli } \\
\text { C } \\
\text { Rcol0226 }\end{array}$ & $\begin{array}{c}\text { T. rangeli } \\
\text { D } \\
\text { SC58 }\end{array}$ & $\begin{array}{c}\text { T. rangeli } \\
\text { E } \\
(643)\end{array}$ & $\begin{array}{l}\text { T. cruzi I } \\
\text { (Dm28) }\end{array}$ & $\begin{array}{l}\text { T. cruzi II } \\
\text { (Y) }\end{array}$ & $\begin{array}{l}\text { T. cruzi III } \\
\text { (MT3663) }\end{array}$ & $\begin{array}{c}\text { T. cruzi } \\
\text { IV } \\
\text { José Julio }\end{array}$ & $\begin{array}{c}\text { T. cruzi } \\
\text { V } \\
(967)\end{array}$ & $\begin{array}{l}\text { T. cruzi } \\
\text { VI (CL } \\
\text { Brener) }\end{array}$ & $\begin{array}{l}\text { T. cruzi } \\
\text { bat } \\
\text { Ort07-1 }\end{array}$ & $\begin{array}{c}\text { T. cruzi } \\
\text { marinkellei } \\
\text { ChaQ 08-1 }\end{array}$ \\
\hline $\begin{array}{l}\text { Rhodnius } \\
\text { prolixus } \\
\text { domestic- } \\
\text { Boyacá }\end{array}$ & - & - & LYSIS & - & LYSIS & - & LYSIS & LYSIS & AGGL & LYSIS & LYSIS & LYSIS & LYSIS \\
\hline $\begin{array}{l}\text { Rhodnius } \\
\text { prolixus } \\
\text { Sylvatic- } \\
\text { Casanare }\end{array}$ & - & - & LYSIS & - & LYSIS & - & LYSIS & LYSIS & AGGL & LYSIS & LYSIS & LYSIS & LYSIS \\
\hline $\begin{array}{l}\text { Rhodnius } \\
\text { robustus }\end{array}$ & - & - & LYSIS & - & LYSIS & - & LYSIS & LYSIS & AGGL & LYSIS & LYSIS & LYSIS & LYSIS \\
\hline $\begin{array}{l}\text { Rhodnius } \\
\text { colombiensis }\end{array}$ & - & - & - & - & - & - & - & - & - & - & - & - & - \\
\hline $\begin{array}{l}\text { Rhodnius } \\
\text { pallescens }\end{array}$ & - & - & - & - & - & - & - & - & - & - & - & - & - \\
\hline $\begin{array}{l}\text { Rhodnius } \\
\text { pictipes }\end{array}$ & - & - & - & - & - & - & - & - & - & - & - & - & - \\
\hline $\begin{array}{l}\text { Triatoma } \\
\text { dimidiata }\end{array}$ & - & - & - & - & - & - & - & - & - & - & - & - & - \\
\hline $\begin{array}{l}\text { Triatoma } \\
\text { maculata }\end{array}$ & - & - & - & - & - & - & - & - & - & - & - & - & - \\
\hline $\begin{array}{l}\text { Panstrongylus } \\
\text { geniculatus }\end{array}$ & - & - & - & - & - & - & - & - & - & - & - & - & - \\
\hline
\end{tabular}

AGGL = Strong agglutination; (-) = No lysis was observed

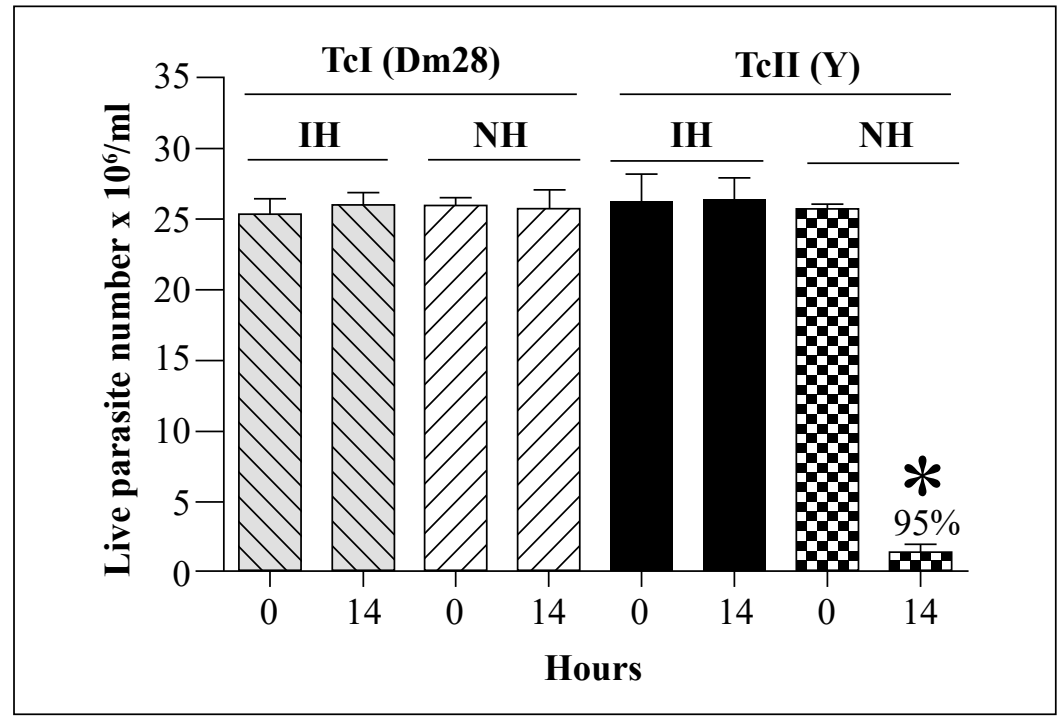

Figure 3. In vitro survival of $T$. cruzi TcI (Dm28) and TcII (Y) strains following incubation with hemolymph from $R$. prolixus

Each bar represents the mean \pm SD of live parasite counts from three independent assays after 0 and $14 \mathrm{~h}$ of incubation with hemolymph. Each T. cruzi strain was incubated with inactivated hemolymph (IH) or native hemolymph (NH).

*: $\mathrm{p}<0.05$ compared with the live parasite counts of the T. cruzi TcI and the TcII strains incubated with $\mathrm{NH}$ at the same time point 


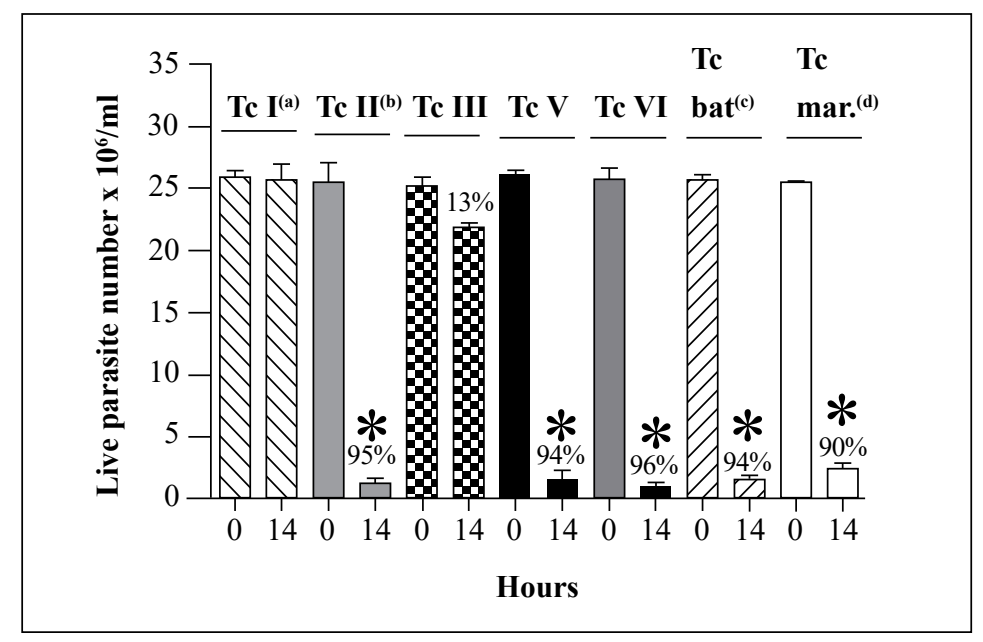

Figure 4. Summary of in vitro survival of $T$. cruzi strains belonging to six different DTUs, as well as one $T$. cruzi subspecies (T. cruzi marinkellei), following incubation with native hemolymph from $R$. prolixus.

Each $T$. cruzi marinkellei bar represents the mean $\pm \mathrm{SD}$ of live parasites counts from three independent assays after 0 and $14 \mathrm{~h}$ of incubation with hemolymph. TcI (Dm28), TcII (Y), TcIII (MT3663), TcV (967), TcVI (CL Brener), Tcbat (Ort07-1), and T. cruzi marinkellei (ChaQ 08-1) strains were examined in this assay. a, Lysis resistance was observed in $20 \mathrm{TcI}$ strains. ${ }^{\mathrm{b}}$, Lysis susceptibility was observed in two TcII strains. ', Lysis susceptibility was observed in six Tcbat strains. ${ }^{\text {d, Lysis }}$ susceptibility was observed in two T. cruzi marinkellei strains. Only one strain was examined for each of the TcIII, TcV, and TcVI DTUs (Table 1). T. cruzi TcI strain Dm28 and TcII strain Y were used as negative (absence of lysis) and positive (presence of lysis) controls, respectively, for assays with TcIII, TcV, TcVI, Tcbat, and T. cruzi marinkellei strains. ${ }^{*}, \mathrm{p}<0.05$ compared with the live parasite counts of the negative controls with the native hemolymph $(\mathrm{NH})$ at the same time point.

worth noting that none of the $R$. colombiensis, $R$. pallescens, $R$. pictipes, T. dimidiata, $T$. maculate, and P. geniculatus hemolymphs had lytic activity against $T$. rangeli and $T$. cruzi strains incubated in the same experimental conditions used here indicating the absence of trypanolytic activity in their hemolymphs during the first 24 hours of incubation.

\section{Comparison of hemolymph from triatomines from wild and laboratory colonies}

Next, we examined whether the maintenance of insects in laboratory colonies had any effect on the lytic activity of hemolymph. Hemolymph was obtained from $37 R$. colombiensis specimens captured from palm trees in Coyaima, Colombia, in September 2018. Hemolymph was also extracted from $R$. colombiensis individuals from a colony that has been maintained in the laboratory for 5 years. Assays were conducted using $T$. cruzi TcII strain Y, which is susceptible to lysis. No significant differences in live parasite counts were observed for any of the treatments (Figure 5). Identical results (absence of lysis) were observed when the assay was repeated using hemolymph from a laboratory colony of $T$. dimidiata and specimens captured in sylvatic environments in Boyacá, Colombia, in May 2019 (data not shown).

Effects of parasite culture time on susceptibility to the lytic activity of native hemolymph from R. prolixus

We then compared the susceptibility of recently obtained and long-term cultures of $T$. cruzi TcII strain $\mathrm{Y}$ to lysis by $R$. prolixus hemolymph. The first TcII strain $\mathrm{Y}$ isolate was obtained from recent hemoculture of mouse blood while the second isolate had been maintained in a 4-year culture with weekly subcultures. As shown in Figure 6, the lytic activity of the hemolymph against the two cultures was similar with $95 \%$ and $96 \%$ decreases in T. cruzi live parasite counts following incubation of native hemolymph with 


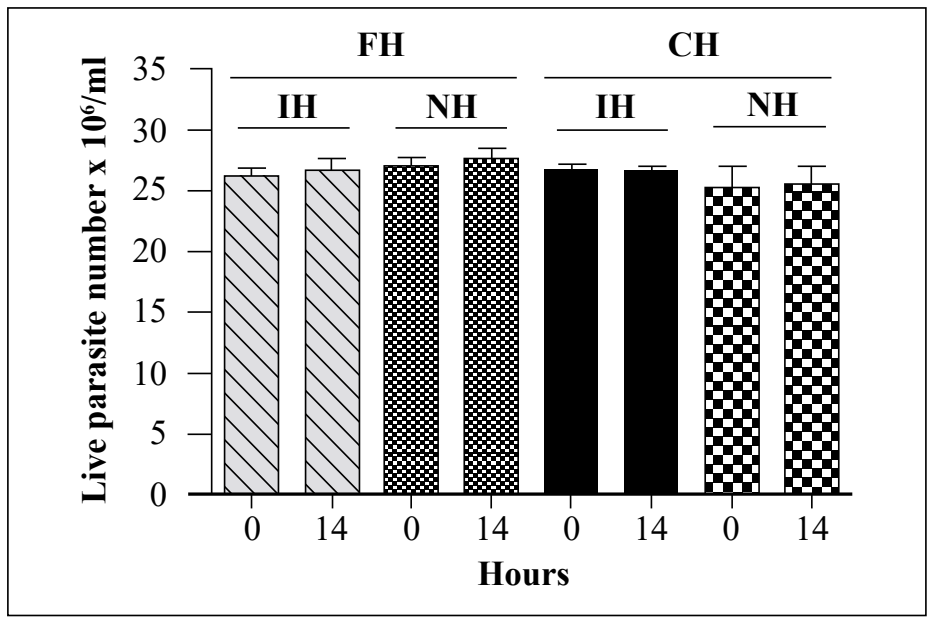

Figure 5. In vitro survival of a $T$. cruzi TcII strain following incubation with hemolymph from laboratory and field-collected $R$. colombiensis insects and comparison of the number of live $T$. cruzi TcII (Y) epimastigotes following incubation with the hemolymph from $R$. colombiensis specimens captured in the field (FH) and hemolymph from $R$. colombiensis individuals from a colony maintained in the laboratory for 5 years $(\mathrm{CH})$. Each bar represents the mean $\pm \mathrm{SD}$ of live parasite counts from two independent assays after 0 and $14 \mathrm{~h}$ of incubation with hemolymph. The T. cruzi parasites were incubated with inactivated hemolymph $(\mathrm{IH})$ or native hemolymph $(\mathrm{NH})$ from both populations.

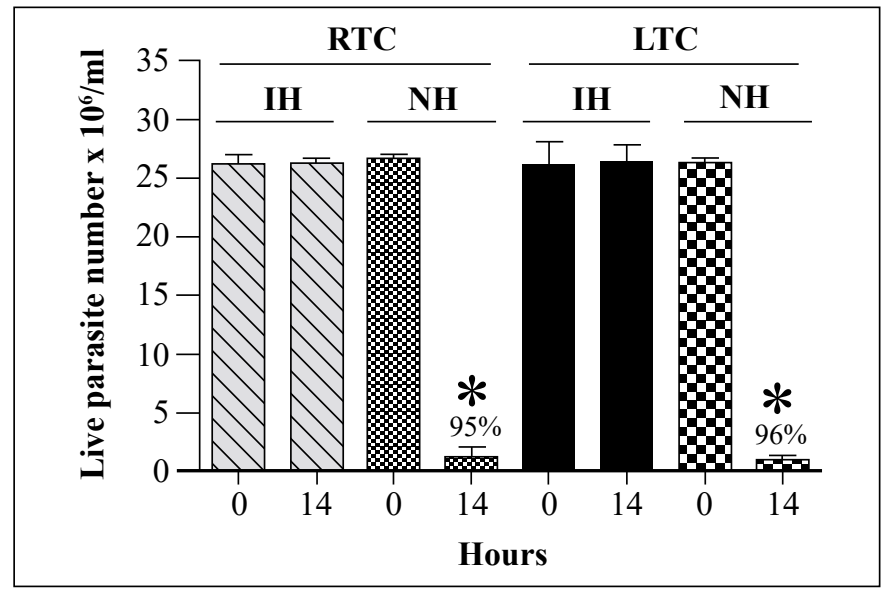

Figure 6. In vitro survival of T. cruzi TcII epimastigotes from recent or long-term cultures following incubation with native hemolymph from $R$. prolixus. $T$. cruzi TcII strain Y isolates recently cultured (recent-term cultivation, RTC) from trypomastigotes from mouse blood or cultured for 4 years (long-term cultivation, LTC) were incubated with native hemolymph from $R$. prolixus. Each bar represents the mean $\pm \mathrm{SD}$ of live parasite counts from three independent assays after 0 and $14 \mathrm{~h}$ of incubation with hemolymph. The same number of $T$. cruzi epimastigotes from the RTC and LTC cultures were incubated with inactivated hemolymph (IH) and native hemolymph $(\mathrm{NH})$. *: $\mathrm{p}<0.05$ compared with live parasite counts of $\mathrm{IH}$ and $\mathrm{NH}$ cultures at the same time point

recently obtained and long-term cultures, respectively. Besides, no lysis of T. rangeli A strain Choachí maintained either via a cyclic culture- $R$. prolixus-mouse-culture method, which allowed us to obtain recent cultures of the parasite, or by weekly subculture for 3 years, was observed following incubation with native hemolymph from $R$. prolixus (data not shown). On the other hand, lysis of T. rangeli $\mathrm{C}$ strain Rcol0226 maintained via a cyclic culture- $R$. colombiensis-mouse-culture method or by weekly subculture for 3 years was observed following incubation with $R$. prolixus native hemolymph (data not shown). 
In addition to the results presented here, we also determined that the lytic activity was similar in hemolymph from vectors fed on chicken or mouse blood and in hemolymph from $R$. prolixus nymphs, males, and females.

\section{Discussion}

The results of the study support previous reports on the existence of a rapid innate response to various $T$. rangeli genotypes and $T$. cruzi DTUs in the hemolymph of $R$. prolixus. Sánchez, et al. (2005) and Pulido, et al. (2008) showed that the epimastigotes of T. rangeli genotype $\mathrm{C}$ strains isolated from $R$. colombiensis, $R$. ecuadoriensis, and $R$. pallescens were lysed when incubated in vitro for $10 \mathrm{~h}$ with hemolymph from $R$. prolixus. In contrast, the epimastigotes of a $T$. rangeli genotype A strain were completely resistant to lysis under the same conditions. In the present work, T. rangeli genotype A, B, and D strains were resistant to lysis during incubation with hemolymph from $R$. prolixus for $24 \mathrm{~h}$ while $81 \%$ and $90 \%$ decreases in live parasite counts were observed for genotype $\mathrm{C}$ and $\mathrm{E}$ strains after $14 \mathrm{~h}$ of incubation with the hemolymph (Figure 2, Table 2).

In vivo assays where the hemocoel of $R$. prolixus was inoculated with $T$. rangeli genotype $\mathrm{C}$ strains showed the rapid disappearance of the flagellated parasite from the hemolymph of the vector (data not shown). This is consistent with the results of Sánchez, et al. (2005) regarding the complete clearance of $T$. rangeli genotype $\mathrm{C}$ cells from the hemolymph at $2 \mathrm{~h}$ post-inoculation. In contrast, inoculated $T$. rangeli genotype A cells were observed in the hemolymph of $T$. rangeli for several months with the production of infective metacyclic trypomastigotes (Vallejo, et al., 1986). As a result, this inoculation method is commonly used to obtain infective trypomastigotes of $T$. rangeli genotype A strains. Similar findings had already been reported by Mello, et al. (1995), who inoculated T. rangeli strain San Agustín (genotype A from Colombia) into the hemocoel of $R$. prolixus. The researchers observed the multiplication of the parasite in the hemolymph for several days with elevated levels of lysozyme activity in the hemolymph but no trypanolytic or antimicrobial peptide activity.

Under experimental conditions, T. rangeli genotype A strains are not lysed following inoculation into the $R$. prolixus hemocoel while genotype $\mathrm{C}$ strains are lysed. This innate lytic response would explain why after characterizing more than $100 \mathrm{~T}$. rangeli strains isolated from the salivary glands of $R$. prolixus from Colombia, Honduras, and Venezuela (Salazar-Anton, et al., 2009), wild Rhodnius neglectus from the Federal District of Brazil (Gurguel-Goncalves, et al., 2004; Urrea, et al., 2005), wild $R$. prolixus from Casanare, Colombia (Urrea, et al., 2011), and R. robustus from Venezuela and Brazil were found to be genotype A (Maia da Silva, et al., 2007; Vallejo, et al., 2015). In these studies, none of the $R$. prolixus, $R$. robustus or $R$. neglectus vectors were infected with genotype $\mathrm{C}$ or $\mathrm{E}$ strains, which are susceptible to hemolymph lysis.

Trypanosoma rangeli genotype $\mathrm{C}$ strains have been isolated from wild $R$. pallescens colonies from Panamá and Colombia, from wild $R$. colombiensis colonies from central Colombia, and from domesticated $R$. ecuadoriensis in the northern region of Perú (Urrea, et al., 2005; Vallejo, et al., 2015). No trypanolytic activity was detected in the hemolymph of these vectors and no lysis was observed following experimental inoculation of a $T$. rangeli genotype A strain into the hemocoel of $R$. colombiensis and $R$. pallescens, although the parasites did not invade the salivary glands (data not shown).

The absence of lytic activity in the hemolymph of Triatoma and Panstrongylus species (T. dimidata, T. maculata, and P. geniculatus) in the current study (Table 2) coincides with the observations of De Stefani-Marques, et al. (2006), who orally infected P. megistus, T. infestans, $T$. sordida, T. braziliensis, and $T$. vitticeps individuals with a strain of $T$. rangeli isolated in Uberaba-Minas Gerais, Brazil, where genotype A predominates. The authors observed the parasites in the hemolymph for 10-30 days following infection without invasion of salivary glands, thus confirming the absence of lytic factors with immediate activity in these vectors. 
The inability of $T$. cruzi to develop in the hemolymph of triatomine vectors was observed in in vivo experiments performed by Alvarenga \& Bronfen (1982), who inoculated T. cruzi strains Y and CL into the hemocoel of T. infestans and Dipetalogaster maxima. They observed that the parasites could not persist in the hemolymph for more than 40 days. In comparison, Mello, et al. (1995) inoculated T. cruzi clone Dm28 into the hemocoel of $R$. prolixus and found that the parasites were completely cleared by day 5 post-inoculation suggesting that the humoral response in hemolymph from $R$ prolixus against $T$. cruzi is faster than that in hemolymph from T. infestans and D. maxima. Early and strong lytic activity was previously observed by Mello, et al. (1996) in in vitro experiments with various $T$. cruzi strains. The authors observed trypanolytic activity in the hemolymph of $R$. prolixus against $T$. cruzi strain Y but not against strains Dm28c or $\mathrm{CL}$ after $3 \mathrm{~h}$ of incubation. Thus, $T$. cruzi clearance depends on both the parasite strain and the vector species. However, the exact mechanism that causes T. cruzi to die in the hemocoel but thrive in the gastrointestinal tract remains unknown (Salcedo-Porras \& Lowenberger, 2019).

Although under natural conditions $T$. cruzi does not enter the hemolymph of the vectors, we decided to use epimastigotes of $T$. cruzi belonging to various DTUs to detect the presence of trypanolytic factors related to an innate immune response in the vectors. Differences in susceptibility to lysis were observed amongst the $T$. cruzi strains belonging to different DTUs, with a TcIII strain showing a $13 \%$ decrease in live parasite numbers after $14 \mathrm{~h}$ of incubation, while a TcI strain remained unaffected after $24 \mathrm{~h}$ of incubation. We observed strong in vitro lytic activity during incubation of $T$. cruzi with hemolymph from $R$. prolixus, with 90\%-96\% decreases in live parasite counts recorded in the first 14 $\mathrm{h}$ of incubation (Figure 4). We could not determine the cause of this variability; however, susceptibility or resistance to lysis of $T$. cruzi strains belonging to different DTUs and $T$. rangeli strains belonging to different genotypes may be related to the ability of the different strains to survive the oxidative stress of the hemolymph. It is likely that the parasites that showed resistance to lysis maintain a repertoire of genes involved in oxidative stress tolerance, which would aid in survival under environmental stress conditions. The variability of the antioxidant defenses of the various $T$. cruzi and $T$. rangeli strains may reflect specific adaptations to the vector species (Stoco, et al., 2014; Beltrame-Botelho, et al., 2016). However, the most intriguing result of the present study was that none of the other vector species, including $R$. pallescens, $R$. colombiensis, $R$. pictipes, T. dimidiata, $T$. maculata, and P. geniculatus, showed hemolymph lytic activity against any of the $T$. cruzi or $T$. rangeli strains after $24 \mathrm{~h}$ of incubation (Table 2).

The lytic activity of hemolymph from field-collected insects and laboratory colonies of $R$. colombiensis (Figure 5) and of $T$. dimidiata against TcII was not observed in any of the hemolymph samples indicating that the absence of lytic activity is independent of the maintenance of colonies in the laboratory. Similarly, lytic activity tests against TcII using R. prolixus colonies from six different departments in Colombia (Boyacá, Casanare, Cundinamarca, Magdalena, Santander, and Tolima) showed equivalent levels of lytic activity in hemolymph from all colonies.

We also found that there was no difference in the lytic susceptibility of T. cruzi TcII epimastigotes recently obtained by blood culture and those maintained in culture for 4 years with weekly subcultures (Figure 6), which indicates that the maintenance time of epimastigotes in culture does not affect their susceptibility to lysis caused by the native hemolymph from $R$. prolixus. There were no differences either in the trypanolytic activity of hemolymph from $R$. prolixus adults (males and females) and fifth-instar nymphs or in hemolymph from insects fed on chicken or mouse blood.

A question that is yet to be resolved is whether these innate trypanolytic factors detected in the hemolymph could also be activated in the intestine to modulate the transmission of intestinal $T$. cruzi parasites. More studies are needed to address this hypothesis, identify innate trypanolytic factors, locate production sites, and determine circulation dynamics and their effector activities in different vector organs and tissues. 
Regarding the possible mechanisms related to hemolymph lytic activity, it is known that prophenoloxidase system (PPO) activation leads to melanin synthesis by indolquinone polymerization. Both melanin and the intermediary products formed during its synthesis help kill bacteria, viruses, and parasites (Walters \& Ratcliffe, 1983; Söderhäll \& Cerenius, 1998; Cerenius, et al., 2008, Azambuja, et al., 2017). PPO availability in the hemolymph of the insects is derived from hemocyte lysis (Kanost and Gorman, 2008). Hemocyte lysis mainly occurs after exposure to microorganisms (Brehélin, et al., 1989), but may also occur spontaneously to maintain basal prophenoloxidase (PPO) levels in hemolymph (Kanost \& Gorman, 2008). Hemolymphs from the eight triatomine species were used in all the parasite incubation experiments in our study; they were hemocyte-free and treated with phenylthiourea, which would have prevented basal PPO levels activation. In principle, the lytic activity observed in $R$. prolixus and $R$. robustus hemolymph should not have been attributed to PPO activation but related to factors other than the PPO cascade.

In a previous study, it was found that $R$. prolixus hemolymph lytic factors or their precursors were proteins (Pulido, et al., 2008); here, we confirmed this finding because hemolymph lytic activity disappeared completely after pepsin incubation. It can be predicted, then, that potential lytic factors or their precursors are proteins and could be antimicrobial peptides (AMP), precursors of reactive nitrogen species (NOS) or reactive oxygen species (ROS) or nitrophorins that are NOS transporters or proteins not yet identified. Proteomic and transcriptomic studies comparing vector species having or lacking lytic activity should be carried out to identify possible candidates and subsequent tests performed to confirm their role in hemolymph lytic activity.

The strategies used by T. rangeli and $T$. cruzi to achieve successful vector infection depend on a tripartite interaction among the parasite, the insect's immune system, and the intestinal microbiota. Experimental infection studies using different bacterial species have shown species-specific differences in the intestinal immune response of the vectors (Vieira, et al., 2014). These interactions constitute an important field of research that will open new perspectives on our understanding of parasite-vector relationships. As part of this tripartite interaction, it will be very important to characterize the microbiomes of insect populations that have a very strong innate humoral response, such as that detected in $R$. prolixus and R. robustus. Investigations of this tripartite interaction could lead to the identification of intestinal microbial species that naturally induce an immune response in the intestine or hemolymph of the vector to avoid parasite infection. Further research is needed to identify the components of the strong differential immune response between insects having and lacking lytic activity to verify whether such factors could be involved in $T$. rangeli genotypes and T. cruzi DTUs' predominance in Colombia and some Latin American regions.

\section{Conclusions}

Using in vitro incubations of $T$. rangeli and $T$. cruzi epimastigotes from different genotypes and DTUs with the hemolymph of eight species of triatomines, we detected strong trypanolytic activity in the hemolymph from $R$. prolixus and $R$. robustus, which was absent in that from $R$. colombiensis, $R$. pallescens, $R$. pictipes, $T$. dimidiata, T. maculata, and $P$. geniculatus. The trypanolytic activity was independent of the sex and stage of the insect, the time the epimastigotes were maintenance in culture, and the type of food on which the vectors were fed (chicken or mouse blood). The absence of trypanolytic activity was observed in both laboratory colonies and field-captured insects of the species $R$. colombiensis and T. dimidiata. There are still gaps in our understanding of the innate immune responses of different triatomine species against the same strains of T. cruzi and T. rangeli or the same triatomine species against geographically-separated isolates of $T$. cruzi and T. rangeli. Interactions between triatomines and trypanosomes involve complex ecological, biochemical, and coevolutionary relationships that are just beginning to be 
investigated. Understanding the factors that determine how a vector is infected and how the parasite is transmitted is key to the success of control programs targeting Chagas disease vectors; unfortunately, most of these factors are unknown. Therefore, it is vital to investigate the ecological, physiological, and immunological factors that determine how and why the vectors transmit some genotypes of the parasite and others do not.

\section{Acknowledgments}

This work was funded by the Colombian Science, Technology and Innovation Department (Colciencias) (grant number 110551929038) and the University of Tolima Research Fund (grant numbers 410010, 430111, and 750213). The authors would like to thank Dr. Marta M. G. Teixeira from the Universidade de São Paulo, Brazil, for kindly providing various $T$. cruzi DTU and T. rangeli genotype reference strains. We are grateful to Dr. Victor Manuel Angulo Silva from the Universidad Industrial de Santander, Colombia, for providing $P$. geniculatus to establish a colony in the LIPT and to Dr. Jairo Alfonso Clavijo from the Mathematics and Statistics Department, Universidad del Tolima, for helping with the statistical analysis. We thank Tamsin Sheen, PhD, from the Edanz Group (www. edanzediting.com/ac) and Jason Garry for editing a draft of this manuscript.

\section{Author Contributions}

Conceptualization: YSQ, JCCM, FGN, GAV. Data curation and Formal analysis: YSQ, HJBV, SAGG, JLOM, DZG, JCCM, GAV. Funding acquisition: YSQ, JCCM, GAV. Investigation: YSQ, HJBV, SAGG, JLOM, DZG, FGN, OCB, JCCM, GAVa. Methodology: YSQ, GAV. Project administration: JCCM, GAV. Technical and biological resources: YSQ, FGN, OCB, JCCM, GAV. Supervision: JCCM, GAV. Writing-original draft: YSQ, GAV. Writing-review\&editing: YSQ, HJBV, SAGG, JLOM, DZG, FGN, OCB, JCCM, GAV.

\section{Conflicts of interest}

The authors declare that there are no conflicts of interest related to the contents of this article.

\section{References}

Alvarenga, N.J. \& Bronfen, E. (1982). Incapacity of the evolution of Trypanosoma cruzi in the hemocele of triatomids. Mem Inst Oswaldo Cruz. 77(4): 431-6. Portuguese.

Azambuja, P., García, E.S., Waniek, P.J., Vieira, C.S., Figueiredo, M.B., Gonzalez, M.S., Mello, C.B., Castro, D.P., Ratcliffe, N.A. (2017). Rhodnius prolixus: From physiology by Wigglesworth to recent studies of immune system modulation by Trypanosoma cruzi and Trypanosoma rangeli. J Insect Physiol. 97: 45-65. Doi: 10.1016/j.jinsphys.2016.11.006

Baker, J.R., Miles, M.A., Godfrey, D.G., Barrett, T.V. (1978). Biochemical characterization of some species of Trypanosoma (Schizotrypanum) from bats (Microchiroptera). Am J Trop Med Hyg. 27(3): 483-91.

Beltrame-Botelho, I.T., Talavera-López, C., Andersson, B., Grisard, E.C., Stoco, P.H. (2016). A Comparative In Silico Study of the Antioxidant Defense Gene Repertoire of Distinct Lifestyle Trypanosomatid Species. Evol Bioinform Online. 12: 263-275.

Brehélin, M., Drift, L., Baud, L., Boemare, N. (1989). Insect haemolymph: Cooperation between humoral and cellular factors in Locusta migratoria. Insect Biochem. 19: 301-309.

Brisse, S., Verhoef, J., Tibayrenc, M. (2001). Characterisation of large and small subunit rRNA and mini-exon genes further support the distinction of six Trypanosoma cruzi lineages. Int J Parasitol. 31 (11): 1218-26. Doi: 10.1016/ S0020-7519(01)00238-7

Buarque, D.S., Braz, G.R., Martins, R.M., Tanaka-Azevedo, A.M., Gomes, C.M., Oliveira, F.A., Schenkman, S., Tanaka, A.S. (2013). Differential expression profiles in the midgut of Triatoma infestans infected with Trypanosoma cruzi. PLoS Negl. Trop. Dis. 5: e61203.

Castro, D.P., Moraes, C.S., Gonzalez, M.S., Ratcliffe, N.A., Azambuja, P., Garcia, E.S. (2012). Trypanosoma cruzi immune response modulation decreases microbiota in Rhodnius prolixus gut and is crucial for parasite survival and development. PLoS One. 7: e36591. 
Cerenius, L., Lee, B.L., Söderhäll, K. (2008). The proPO-system: Pros and cons for its role in invertebrate immunity. Trends Immunol. 29: 263-271. Doi: 10.1016/j.it.2008.02.009.

De Fuentes-Vicente, J.A., Cabrera-Bravo, M., Enríquez-Vara, J.N., Bucio-Torres, M.I., Gutiérrez-Cabrera, A.E., Vidal-López, D.G., Martínez-Ibarra, J.A., Salazar-Schettino, P.M., Córdoba-Aguilar, A. (2016). Relationships between altitude, triatomine (Triatoma dimidiata) immune response and virulence of Trypanosoma cruzi, the causal agent of Chagas' disease. Med. Vet. Entomol. 31: 63-71.

De Stefani-Márquez, M.D., Rodrigues-Ottaiano, C., Mônica Oliveira, R., Pedrosa, A.L., CabrineSantos, M., Lages-Silva, E., Ramírez, L.E. (2006). Susceptibility of different triatomine species to Trypanosoma rangeli experimental infection. Vector Borne Zoonotic Dis. 6 (1): 50-56.

Figueiredo, M.B., Genta, F.A, Garcia, E.S., Azambuja, P. (2008). Lipid mediators and vector infection: Trypanosoma rangeli inhibits Rhodnius prolixus hemocyte phagocytosis by modulation of phospholipase A2 and PAF-acetylhydrolase activities. J Insect Physiol. 54: 1528-37.

Galvão, C. \& Justi, S.A. (2015). An overview on the ecology of Triatominae (Hemiptera: Reduviidae). Acta Trop. 151: 116-25. Doi: 10.1016/j.actatropica.2015.06.006.

García, E.S., Machado, E.M., Azambuja, P. (2004a). Inhibition of hemocyte microaggregation reactions in Rhodnius prolixus larvae orally infected with Trypanosoma rangeli. Exp Parasitol. 107: 31-8.

García, E.S., Machado, E.M., Azambuja, P. (2004b). Effects of eicosanoid biosynthesis inhibitors on the prophenoloxidase-activating system and microaggregation reactions in the hemolymph of Rhodnius prolixus infected with Trypanosoma rangeli. J Insect Physiol. 50: 157-65.

Guhl, F. \& Vallejo, G.A. (2003). Trypanosoma (Herpetosoma) rangeli Tejera, 1920: An updated review. Mem Inst Oswaldo Cruz. 98(4): 435-42.

Gurgel-Gonçalves, R., Ramalho, E.D., Duarte, M.A., Palma, A.R., Abad-Franch, F., Carranza, J.C., Cuba-Cuba, C.A. (2004). Enzootic transmission of Trypanosoma cruzi and T. rangeli in the Federal District of Brazil. Rev Inst Med Trop Sao Paulo. 46 (6):323-30.

Hoare, C.A. (1972). The trypanosomes of mammals: A zoological monograph. Oxford: Blackwell Scientific Publications. 749 p.p.

Kanost, M.R., Gorman, M.J. (2008). Phenoloxidases in insect immunity. In: Beckage,N. (Ed.), Insect Immunology. Academic Press/Elsevier, San Diego, p. 69-96.

López, L., Morales, G., Ursic, R., Wolff, M., Lowenberger, C. (2003). Isolation and characterization of a novel insect defensin from Rhodnius prolixus: A vector of Chagas disease. Insect Biochem. Mol. Biol. 33: 349-447.

Maia Da Silva, F., Junqueira, A.C., Campaner, M., Rodrigues, A.C., Crisante, G., Ramírez, L.E., Caballero, Z.C., Monteiro, F.A., Coura, J.R., Añez, N., Teixeira, M.M. (2007). Comparative phylogeography of Trypanosoma rangeli and Rhodnius (Hemiptera: Reduviidae) supports a long coexistence of parasite lineages and their sympatric vectors. Mol Ecol. 16 (16): 3361-73.

Marcili, A., Lima, L., Cavazzana, M., Junqueira, A.C., Veludo, H.H., Maia Da Silva, F., Campaner, M., Paiva, F., Nunes, V.L., Teixeira, M.M. (2009). A new genotype of Trypanosoma cruzi associated with bats evidenced by phylogenetic analyses using SSU rDNA, cytochrome $\mathrm{b}$ and Histone $\mathrm{H} 2 \mathrm{~B}$ genes and genotyping based on ITS1 rDNA. Parasitology. 136 (6): 641-55.

Mello, C.B., García, E.S., Ratcliffe, N.A., Azambuja, P. (1995). Trypanosoma cruzi and Trypanosoma rangeli: Interplay with hemolymph components of Rhodnius prolixus. J Invertebr Pathol. 65 (3): 261-8.

Mello, C.B., Azambuja, P., Garcia, E.S., Ratcliffe, N.A. (1996). Differential in vitro and in vivo behavior of three strains of Trypanosoma cruzi in the gut and hemolymph of Rhodnius prolixus. Exp. Parasitol. 82: 112-121.

Pereira ME, Andrade AF, Ribeiro JM. (1981). Lectins of distinct specificity in Rhodnius prolixus interact selectively with Trypanosoma cruzi. Science. 211: 597-600.

Pulido, X.C., Pérez, G., Vallejo, G.A. (2008). Preliminary characterization of a Rhodnius prolixus hemolymph trypanolytic protein, this being a determinant of Trypanosoma rangeli $\mathrm{KP} 1(+)$ and KP1(-) subpopulations' vectorial ability. Memorias do Instituto Oawaldo Cruz. 103 (2): 172-179.

Salazar-Antón, F., Urrea, D.A., Guhl, F., Arévalo, C., Azofeifa G., Urbina A., Blandón-Naranjo, M. Sousa, O.E., Zeledón, R., Vallejo, G.A. (2009). Trypanosoma rangeli genotypes association with Rhodnius prolixus and $R$. pallescens allopatric distribution in Central America. Infection, Genetics and Evolution. 9: 1306-1310. 
Salcedo-Porras, N. \& Lowenberger, C. (2019). The innate immune system of kissing bugs, vectors of chagas disease. Dev Comp Immunol. 98: 119-128. Doi: 10.1016/j.dci.2019.04.007.

Sánchez, I.P., Pulido, X.C., Carranza, J.C., Triana, O., Vallejo, G.A. (2005). Inmunidad Natural de Rhodnius prolixus (Hemiptera: Reduviidae: Triatominae) frente a la infección con Trypanosoma (Herpetosoma) rangeli KP1(-) aislados de Rhodnius pallescens, $R$. colombiensis y R. ecuadoriensis. Revista de la Asociación Colombiana de Ciencias Biológicas. 17: 108-118.

Söderhäll, K. \& Cerenius, L. (1998). Role of the prophenoloxidase-activating system ininvertebrates. Curr Opi. Immunol. 10: 23-28

Souto, R.P. \& Zingales, B. (1993). Sensitive detection and strain classification of Trypanosoma cruzi by amplification of a ribosomal RNA sequence. Mol Biochem Parasitol. 62 (1): 45-52. Doi: /10.1016/0166-6851(93)90176-X

Souto, R.P., Fernandes, O., Macedo, A.M., Campbell, D.A., Zingales, B. (1996). DNA markers define two major phylogenetic lineages of Trypanosoma cruzi. Mol Biochem Parasitol. 83 (2): 141-52. Doi: 10.1016/S0166-6851(96) 02755-7

Stoco, P.H., Wagner, G., Talavera-Lopez, C., Gerber, A., Zaha, A., Thompson, C.E., Bartholomeu, D.C., Lückemeyer, D.D., Bahia, D., Loreto, E., Prestes, E.B., Lima, F.M., Rodrigues-Luiz, G., Vallejo, G.A., Filho, J.F., Schenkman, S., Monteiro, K.M., Tyler, K.M., Almeida, L.G., Ortiz, M.F., Chiurillo, M.A., Moraes, M.H., Cunha Ode. L., Mendonça-Neto, R., Silva, R., Teixeira, S.M., Murta, S.M., Sincero, T.C., Mendes, T.A., Urmenyi, T.P., Silva, V.G., Da Rocha, W.D., Andersson, B., Romanha, A.J., Steindel, M., Vasconcelos, A.T., Grisard, E.C. (2014). Genome of the Avirulent Human-Infective Trypanosome-Trypanosoma rangeli. PLoS Negl. Trop. Dis. 8 (9): e3176. Doi: 10.1371/ journal.pntd.0003176

Urrea, D.A., Carranza, J.C., Cuba-Cuba, C.A., Gurgel-Gonçalves, R., Guhl, F., Schofield, C.J., Triana O., Vallejo, G.A. (2005). Molecular characterisation of Trypanosoma rangeli strains isolated from Rhodnius ecuadoriensis in Perú, $R$. colombiensis in Colombia and $R$. pallescens in Panamá supports a co-evolutionary association between parasites and vectors. Infection, Genetics and Evolution. 5 (2): 123-129.

Urrea, D.A., Herrera, C.P., Falla, A., Carranza, J.C., Cuba-Cuba, C., Triana-Chávez, O., Grisard, E.C., Guhl, F., Vallejo, G.A. (2011). Sequence analysis of the splicedleader intergenic region (SL-IR) and random amplified polymorphic DNA (RAPD) of Trypanosoma rangeli strains isolated from Rhodnius ecuadoriensis, $R$. colombiensis, $R$. pallescens and $R$. prolixus suggests a degree of co-evolution between parasites and vectors. Acta Tropica. 120: 59-66.

Ursic-Bedoya, R.J., Nazzari, H., Cooper, D., Triana, O., Wolff, M., Lowenberger, C. (2008). Identification and characterization of two novel lysozymes from Rhodnius prolixus, a vector of Chagas disease. J. Insect. Physiol. 54: 593-603.

Ursic-Bedoya, R., Buchhop, J., Joy, J.B., Durvasula, R., Lowenberger, C. (2011). Prolixicin: A novel antimicrobial peptide isolated from Rhodnius prolixus with differential activity against bacteria and Trypanosoma cruzi. Insect. Mol. Biol. 20: 775-786.

Vallejo, G. A., Marinkelle, C. J., Guhl, F., de Sánchez, N. (1986). Mantenimiento en el laboratorio de Trypanosoma (Herpetosoma) rangeli Tejera, 1920. Revista de biología tropical. 34 (1): $75-81$.

Vallejo, G.A., Marinkelle, C.J., Guhl, F., de Sánchez, N. (1988). Behavior of the infection and morphologic differentiation of Trypanosoma cruzi and T. rangeli in the intestine of the vector Rhodnius prolixus. Rev Bras Biol. 48 (3): 577-87. Spanish.

Vallejo, G.A., Guhl, F., Carranza, J.C., Lozano, L.E., Sánchez, J.L., Jaramillo, J.C., Gualtero, D., Castañeda, N., Silva, J.C., Steindel, M. 2002. kDNA markers define two major Trypanosoma rangeli lineages in Latin-America. Acta Trop. 81 (1): 77-82.

Vallejo, G.A., Suárez, Y., Olaya, J.L., Gutiérrez, S.A., Carranza, J.C. (2015). Trypanosoma rangeli: un protozoo infectivo y no patógeno para el humano que contribuye al entendimiento de la transmisión vectorial and la infección por Trypanosoma cruzi, agente causal de la Chagas' disease. Rev. Acad. Col. Cienc. Exac. Fís. Nat. 39 (150): 111-122.

Vieira, C.S., Waniek, P.J., Mattos, D.P., Castro, D.P., Mello, C.B., Ratcliffe, N.A., García, E.S., Azambuja, P. (2014). Humoral responses in Rhodnius prolixus: Bacterial feeding induces differential patterns of antibacterial activity and enhances mRNA levels of antimicrobial peptides in the midgut. Parasit Vectors. 7: 232. Doi: 10.1186/1756-3305-7-232

Vieira, C.S., Mattos, D.P., Waniek, P.J., Santangelo, J.M., Figueiredo, M.B., Gumiel, M., da Mota, F.F., Castro, D.P., Garcia, E.S., Azambuja, P. (2015). Rhodnius prolixus interaction with Trypanosoma rangeli: Modulation of the immune system and microbiota population. Parasit Vectors. 8: 135. Doi: 10.1186/s13071-015-0736-2 
Vieira, C.S., Waniek, P.J., Castro, D.P., Mattos, D.P., Moreira, O.C., Azambuja, P. (2016). Impact of Trypanosoma cruzi on antimicrobial peptide gene expression and activity in the fat body and midgut of Rhodnius prolixus. Parasit.Vectors. 9: 119. Doi: 10.1186/s13071-016$1398-4$

Villa, L.M., Guhl, F., Zabala, D., Ramírez, J.D., Urrea, D.A., Hernández, D.C., Cucunubá, Z., Montilla, M., Carranza, J.C., Rueda, K., Trujillo, J.E., Vallejo, G.A. (2013). The identification of two Trypanosoma cruzi I genotypes from domestic and sylvatic transmission cycles in Colombia based on a single polymerase chain reaction amplification of the splicedleader intergenic region. Mem Inst Oswaldo Cruz. 108 (7): 932-5. Doi: 10.1590/00740276130201

Walters, J. \& Ratcliffe, N.A. (1983). Studies on the in vivo cellular reactions of insects: Fate of pathogenic and non-pathogenic bacteria in Galleria mellonellanodules. J Insect Physio. 29: 417-424. Doi: 10.1016/0022-1910(83)90069-0

Whitten, M., Sun, F., Tew, I., Schaub, G., Soukou, C., Nappi, A., Ratcliffe, N. (2007). Differential modulation of Rhodnius prolixus nitric oxide activities following challenge with Trypanosoma rangeli, Trypanosoma cruzi and bacterial cell wall components. Insect Biochem. Molec. Biol. 37: 440-452.

Zingales, B., Andrade, S.G., Briones, M.R., Campbell, D.A., Chiari, E., Fernandes, O., Guhl, F., Lages-Silva, E., Macedo, A.M., Machado, C.R., Miles, M.A., Romanha, A.J., Sturm, N.R., Tibayrenc, M., Schijman, A.G. (2009). Second Satellite Meeting. A new consensus for Trypanosoma cruzi intraspecific nomenclature: Second revision meeting recommends TcI to TcVI. Mem Inst Oswaldo Cruz. 104 (7): 1051-4.

Zingales, B., Miles, M.A., Campbell, D.A., Tibayrenc, M., Macedo, A.M., Teixeira, M.M., Schijman, A.G., Llewellyn, M.S., Lages-Silva, E., Machado, C.R., Andrade, S.G., Sturm, N.R. (2012). The revised Trypanosoma cruzi subspecific nomenclature: Rationale, epidemiological relevance and research applications. Infect Genet Evol. 12 (2): 240-53. Doi: 10.1016/j.meegid.2011.12.009 